\title{
Presidential Address 2021 \\ Edges of Science and Challenges of Communication: Confusion in the Community and Finding a Way Forward
}

\author{
Ross A. Hynes
}

\begin{abstract}
Introduction
We live in a period some researchers are calling an Anthropause, a time of crisis, when humanity can and must rethink and change the way it lives on this planet. However, presently in this period of pandemic, climate change and biosphere degradation, many fields of science are both under attack and employed selectively by different actors. There are many reasons. This address briefly overviews the evolving nature of modern science and explores the misuse and negligent use of science and the demanding strategies we may be forced to follow if we are to urgently and intelligently clarify and implement effective change towards an ethical and sustainable future for humankind and our biosphere.
\end{abstract}

\section{A Basic Definition of Scientific Method}

For science to work, it needs to be carried out using rigorous, consistent and ethical methods. Traditionally in the basic process, an hypothesis (an explanation) is proposed, predictions that best fit that hypothesis are developed, and these are tested to see whether they can be proven false. Is this enough in 2021? Science has evolved rapidly over the last century or so across a wide spectrum of scales along a number of pathways. Here I present a rapid summary of these as I understand them, acknowledging at the outset that this can only briefly flag the scope and depth of the expanding knowledge involved.

\section{Pathways of Modern Science (with some defining characteristics)}

The scope of science has changed substantially, particularly since the 1950s. Further, our concepts of scientific certainty and uncertainty have changed dramatically at both the nano and supermacro ends of the scientific scale, examples being the ongoing refinement in our understanding and interpretation of quantum physics and our everexpanding discoveries and insights in the field of cosmology. Let us briefly explore some features that characterise the main approaches.

\section{Traditional (Predictive - following hypothesis testing)}

The traditional method of scientific investigation in the West is widely regarded as stemming from Aristotle (384-322 BC) (Southwell, 2013), through to Newtonian physics (Newton, 1726) ${ }^{1}$, and many other scientists and scientific philosophers to Karl Popper (Popper, 1965, 1972) and then to the present. This pathway has defined the traditional disciplines and operates at defined scales, seeking observational understanding, but since the Enlightenment ( mid1600s) dualistic, 'yes/no' answers. The method is binary, and if the initial hypothesis is falsified, the problem can be redefined in a second hypothesis and the investigation, if justified, starts again. (Nevertheless, most investigations tend to present their findings in terms of orders of confidence using traditional statistics. Statistics, however, can usually

\footnotetext{
${ }^{1}$ Perhaps the most accessible English translation is: Newton, I. (1999). The Principia: Mathematical Principles of Natural Philosophy. Translated by I. Bernard Cohen, Anne Whitman with Julia Budenz. University of California Press.
}

This work is licensed under a Creative Commons Attribution-NonCommercial-NoDerivatives 4.0 International Licence. Individual articles may be copied or downloaded for private, scholarly and not-for-profit use. Quotations may be extracted provided that the author and The Royal Society of Queensland are acknowledged. Queries regarding republication of papers, or parts of papers such as figures and photographs, should be addressed to the Secretary of The Royal Society of Queensland (rsocqld@gmail.com). 
describe only the variation within the set of data generated by the study. It cannot predict beyond this domain.)

This methodological category covers most of basic science such as interpretations and applications of the classical laws of physics, explanations of how elements combine to form compounds, classical experimental design and investigation in physics, chemistry and biology, and the application of most methods of contemporary statistics. This is the basis for the logical positivism that has dominated much of the science of the twentieth century; i.e., only statements of science and maths are meaningful. Some say it has gone too far in this mode.

This method was questioned in part by Thomas Kuhn. He advanced a view of science as proceeding not by careful hypothesis and testing, but by the formation of paradigms (a term introduced by Aristotle) established when by a consensus of key scientific leaders, the concepts on which they form their assumptions and understandings from associated discoveries allow the development of a framework ${ }^{2}$ to progress scientific investigation (Kuhn, 1962). Science, he suggests, advances via radical and abrupt paradigm shifts when the internal contradictions of the prevailing paradigm are unable to explain crucial advances in knowledge. This initiates a scientific revolution and a new paradigm emerges.

Both approaches contribute to the framework within which contemporary science operates and in which relevant theory can place the results of traditional science in context with the traditional peer-review process.

\section{Quantum (Predictive - but with uncertainty)}

This field of enquiry examines the strange and wonderful world of sub-atomic particle physics in seeking an understanding of how entities behave at a nano scale and has been the subject of scientific investigation for more than 120 years. Various descriptors have been used: 'weird', 'fuzzy' and 'baffling'. (A nanometre is $10^{-9}$ metres, i.e. one billionth of a metre.)
In 1900 Max Planck assumed that radiation emitted from a perfectly absorbing 'black body' comes in the form of discrete packages of energy or quanta. Albert Einstein, following this in 1905, assumed that quanta were real and act like discrete, particle-like entities called photons (Brooks, 2021). Heisenberg's uncertainty principle (Heisenberg, 1930) suggests that we can never be exactly sure of both the position and the velocity of a particle; the more accurately we know the one, the less accurately we can know the other (Hawking, 1988). Richard Feynman calls this the "wave-particle duality", the "only mystery" of quantum physics (Brooks, 2021). Investigations at nano levels of scale presently employ big instrumentation, e.g. CERN, and have led to the discovery of the Higgs boson - the first and only elementary scalar particle yet observed. Fuzzy logic science (Kosko, 1994; Brooks, 2021) simultaneously recognises that in the two states, super-positioning cannot usually be verified.

The status quo has five theoretical models (Brooks, 2021), viz.:

1. Copenhagen interpretation (quantum theory is merely a tool for making predictions keep calculating).

2. Many worlds interpretation (the wave function is real and does not collapse - it splits into many copies of itself, across many worlds).

3. Quantum Bayesianism (provides a way to represent our subjective knowledge, with collapse being a process of updating each observation, and the fuzziness being in our minds).

4. Objective collapse theory (objectively real, quantum reality is independent of the observer, with collapse happening spontaneously with no observers necessary).

5. Pilot wave theory (objectively real and deterministic, with pilot waves guiding the evolution of quantum states into unseen layers of reality - everything is interconnected irrespective of scale).

\footnotetext{
${ }^{2}$ A scientific paradigm contains all the accepted views, conventions about research direction and how it should be conducted in a nominated field; it involves a discrete system of concepts and thought patterns.
} 
There are pros and cons regarding each theory. It is an emerging and somewhat bewildering field not understood by many scientists and not generally understood by the community. Presently, an important intersection is where nano science and quantum physics overlap. If quantum coherent functionality is achieved, then nano-scale applications can be employed with everyday materials, electronics, medical and health applications, energy applications, environmental remediation and numerous resulting products, e.g. water- and stain-resistant clothing and upholstery, sunscreens (titanium oxide), car paints, nano-glues, solar panels, computers (www.nano.gov; www. understandingnano.com; www.en.wikipedia.org/ wiki/industrial_applications_of_nanotechnology).

\section{Big Data-Whole System (Predictive - using big data trend analyses and iterative simulation processes)}

Multivariable, cross-scale, non-linear, whole-systems science (Hynes, 2020) identifies major trends, optimises the application of big data and has integrating power, through simulation models based on defined assumptions that are run, often repeatedly, with increasingly tightened assumptions to seek refined outcomes that better reflect reality. The Intergovernmental Panel on Climate Change's (IPCC) Volume 6 (2021) was prepared by 234 authors who emphasise that their conclusions are based on "multiple lines of evidence". The findings of this big data-whole system approach have been presented with progressively greater confidence since IPCC 1 in 1990 (see Figure 1 for representation of temperature change ranges from Reports 4, 5 and 6, which incrementally predict, at higher levels of confidence, the likelihood of our dire situation). This approach has built upon models that have themselves been tightened progressively since intensive attention became more focused on climate science in the 1980s. Supporting these processes at the analytical and interpretative stages are advanced statistical methods, ever-increasing database stores and more rigorous data quality control. The outputs expressed in terms of probabilities can be frustrating for non-expert stakeholders who seek binary explanations.
Expected warming per doubling of atmospheric carbon dioxide, in degrees Celcius

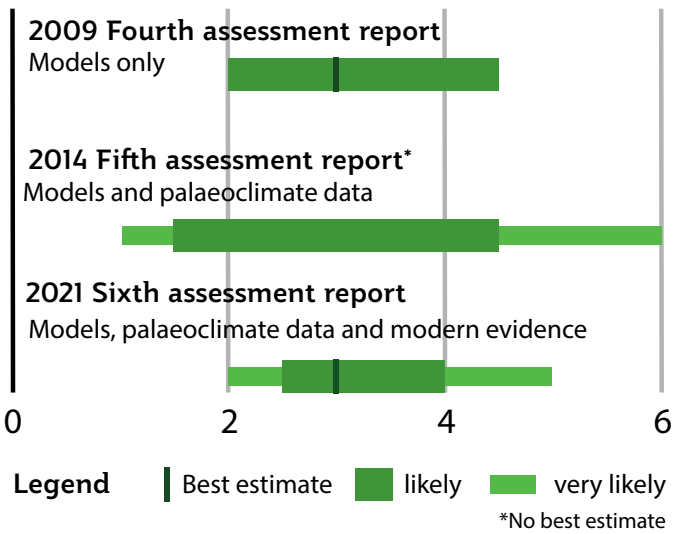

FIGURE 1. A graphic representation of the increasing confidence levels of the likely temperature range predictions as the data employed has been enriched and incorporated in the modelling and analysis process. This is particularly clear between Reports 4 and 6, irrespective of the outcome that indicates the best estimated mean temperature rise is almost identical. (This information has been derived from IPCC Report 6 (2021) and adapted from Anon. (2021, p. 62).)

Most of the current threats to global life-support systems such as global warming, critical loss of biodiversity, pollution and global zoonoses cannot be readily solved using reproducible science methods alone. Why? Because these are whole systems-level problems with solutions needing both the essential findings of reproducible science and the integrating and modelling power of systems science, while being mired in the wider unpredictability of messy human behaviour. A limitation here is that systems science is an immature and simultaneously rapidly developing field.

The effective management and application of big data is integral to success in this pathway. The essential skills needed include: best practices for developing and sharing data, code, software, and entire scientific flows; comprehensive analyses of vast quantities of data on distributed cyberinfrastructure; and collaborative skills in an open science framework that facilitate large-team science (Balch et al., 2020). Parallel to this is an urgent need to develop a strong underlying theoretical base for this level of scientific work. We have not achieved this to date. 
As I mentioned in my 2020 presidential address on this theme (Hynes, 2020, p. 176):

Ecology has recently seen rapid growth, driven mainly by advances in technology, greater access to 'big data' and a growing awareness of the interconnections between humans and natural systems. As a discipline it has expanded beyond traditional themes and reductionist investigations to cover anthropogenic and contemporary datarich, micro- and macro-scale themes. Increased availability of complex data, coupled with advances in technology and analytical capacities (e.g. the relevant use of super computers) have enabled this expansion from a classical theoretical discipline to a data-driven, multidisciplinary science that can apply knowledge to whole systems and their problems.

Clearly, ecological research themes have shifted significantly over the past four decades (McCallan et al., 2019).

Notwithstanding this, without a strong underlying theoretical base, I re-emphasise here: “... denialists presently have relatively easy targets because the current methodologies do not have theoretical and practical coherence, rational tests of connectedness and verifiable understanding of information-flow between levels of scale in space and time" (Hynes, 2020, p. 182). Nevertheless, we do have a kitbag of increasingly powerful digitally based tools and associated instrumentation that needs to be optimised in this context.

To get astronauts to the Moon and back demanded both traditional predictive (reproducible) science results and integrated suites of logically developed systems, which in this instance meant sciencebased engineering. We urgently need a similar but more evolved approach to enable us to proactively address the present global challenges. And we need to look beyond just the bio-geo-physical sciences into the power dynamics operating in public arenas that may distort evidence-based policy analysis.

\section{Reconstructive (Retro-predictive)}

This path seeks to explain the past as a way of better understanding the present. It covers a wide range of big-picture fields: cosmology and relativity (Einstein, 1905, 1915³; Hawking, 1988); tectonic processes, plate tectonics and geomorphology starting with Wegener (1929); archaeology and the evolution of Homo sapiens and culture, biological evolution with genetics and DNA (Darwin, 1859; Mendel, 1866; Watson \& Crick, 1953), and beyond.

There are epistemological challenges that relate to the fields of palaeontology, cosmology, evolutionary biology, geomorphology, plate tectonics, and archaeology to name a few. However, these are not new: the underlying concepts have been actively addressed in a number of these fields for more than 150 years. This is clearly an authentic pathway to engage in scientific investigation.

Also, the methods and tools available for 'reconstructive science' are becoming more powerful. Examples include DNA analysis in evolutionary biology of Homo sapiens and other genetic studies of many other species; and the increasing development of science-based technologies related to cosmology such as higher-powered space-based telescopes, Solar System probes and remote onsurface, technically versatile 'explorers', to list just a few. And these, when linked to the exponentially increasing power of relevant expanding digital databases, make the future of 'reconstructive science' exciting and worthwhile.

Contemporary 'reconstructive "origins" science' uses intensive, prolonged and creative scientific method in conjunction with relevant modelling and statistical methods (e.g. in certain cases, Bayesian statistics) to retro-predict how geological formations, biological evolution, archaeological human cultural evolution, the Solar System, past climates (using for example the planned one-million-year-old ice core by the Australian Antarctic Division), etc., respectively evolved or originated. Notably, the scientists involved and the scientific methods and knowledge bases being developed and implemented are quickly achieving greater rigour over time.

Both 'whole-system' and 'reconstructive' sciences need to critically address issues of time, space and scale. In this setting, twenty-first century challenges can be confusing to our wider society as research

${ }^{3}$ Perhaps the most accessible reference is: Einstein, A. (1952). The Principle of Relativity: A Collection of Original papers on the Special and General Theory of Relativity. Dover. 
groups can selectively employ methods across pathways to strengthen the overall research strategy when investigating these complex problems, particularly in the applied sciences such as medicine, agriculture, and biodiversity conservation.

The science of the big problems, such as climate change, biosphere degradation and pandemics, encompasses all pathways but with varying degrees of application and certainty. The average person usually prefers clear, simple answers, which are presently literally impossible to provide. As explained, a further difficulty is that the status of underlying theory is uneven across the pathways.

Additionally, a sobering current factor in gaining acceptance of scientific knowledge relates to the dynamics of some of those with wealth and power, where facts and the sciences often have little to do with their success in getting their agenda implemented.

This overview is clearly non-exhaustive. In this address I have not included many areas of scientific activity that are worthy of further consideration, e.g. the science underlying $\mathrm{AI}$ and the longer-term potential impacts on human society; nor have I commented on chaos theory, catastrophe theory, Occam's razor or even offered a more penetrating discussion on the epistemology of science. Further, I have not here addressed the acknowledgement and incorporation of First Nations people, their knowledge and epistemology into contemporary science.

However, it is possible to identify some substantive trends and to summarise some in tabular form. The scope of scientific research is obviously changing and continues to change (Table 1). The comparisons presented acknowledge the continuity of traditional science methods, but also show that there is an ongoing exploration, evolution and consolidation of novel and future approaches of scientific research, their outcomes and potential user-relevant deliverables.

Table 1. Changes in the approaches to science and knowledge in the 1990s and beyond (adapted from Gibbon et al., 1994: in Hynes, 1998, 2015).

\begin{tabular}{|c|c|}
\hline Ongoing traditional approach & Strengthening of new and future approaches \\
\hline - Traditional disciplinary and cognitive science & $\begin{array}{l}\text { Multidisciplinary and participatory within a social, } \\
\text { economic and application context }\end{array}$ \\
\hline - Homogeneity of focus & - Heterogeneity of focus \\
\hline - Hierarchical & - Heterarchical and transient structures \\
\hline - Quality control by peers & $\begin{array}{l}\text { Quality control through social, economic and politi- } \\
\text { cal accountability, reflexive and multi-dimensional } \\
\text { collaboration: } \\
\text { - supply and demand of knowledge variable } \\
\text { - production of knowledge rather than science }\end{array}$ \\
\hline - Economy of scale of operations within disciplines & $\begin{array}{l}\text { - Economy of scope across disciplines: } \\
\text { - solutions beyond any single discipline }\end{array}$ \\
\hline $\begin{array}{l}\text { - Communication through institutional channels: } \\
\text { - technology transfer }\end{array}$ & $\begin{array}{l}\text { - Communication through involvement of others: } \\
- \text { technology interchange and linkages of skills and } \\
\text { instructional sites together }\end{array}$ \\
\hline - Research staff on permanent employment & $\begin{array}{l}\text { - Research staff transient, regrouping for particular } \\
\text { issues }\end{array}$ \\
\hline - Management by control & - Management by facilitation \\
\hline - Individual agencies have defined roles and objectives & $\begin{array}{l}\text { - Agencies have fuzzy boundaries and move into and } \\
\text { out of alliances }\end{array}$ \\
\hline - State-wide and centralised decision making & - Regional and catchment-based decision making \\
\hline
\end{tabular}




\section{The Weakening of Bridging Communication Methodologies}

The rundown of agricultural extension and nature conservation interpretive services has severely affected our capacity to translate science into practice, particularly in regional and rural areas. Importantly, both agricultural extension officers and conservation interpretive officers were the eyes and ears of government and were able to feed information from rural communities into government agencies and vice versa:

Extension, technology transfer influencing farming practice, is now very much in the hands of consultants who focus on individual farm businesses. Government-based extension services were also focused on education. I suspect that this is now very much lost (David Lloyd, former principal pasture scientist DPI, pers. comm., 2021).

That said, the complexity of the information environment in 2021 enables an immediate capacity to unthinkingly react to sound scientific information with fake news, cancel culture messaging and conspiracy theories, and exposes the limitations of earlier communication strategies.

The recognition that information does not clearly satisfy the principles of conservation and cyclical flow (Hynes, 1979) is seldom acknowledged, and this has never been more obvious than in the present.

Further, filters (sender, receiver and combination) that degrade the quality and effectiveness of communications (Hynes, 1979) seriously reduce the efficacy of science understanding and uptake. Filters in our current context are significantly more complex, and accurate, fair and trustworthy communication is substantially more difficult to attain.

In an earlier era, attitudinal and behavioural change was usually perceived as moving through four stages (Hynes, 1981). In very simple terms, typical attitudinal and behavioural changes usually advanced often slowly, but sometimes quickly:

- No talk $\rightarrow$ No do; Talk $\rightarrow$ No do; Talk $\rightarrow$ Do; No talk $\rightarrow$ Do;

- 1. No communication $\rightarrow$ No attitudinal or behavioural change.

2. Communication $\rightarrow$ No change.
3. Communication $\rightarrow$ Change.

4. No communication $\rightarrow$ Attitudinal and behavioural change adopted (Hynes, 1981).

Understanding how attitudes and behaviour may change and participatory involvement of stakeholders in identifying relevant, practical solutions to enterprise-related problems can be crucial in linking the people on the ground with scientific research and its application.

However, in the digital age where the tendency for any scientific explanation that is contrary to a particular group's worldview rapidly incurs unjustified outrage, the above model no longer provides an adequate basis for understanding. We need to develop relevant communication techniques and strategies for our time and its technological context. The ongoing enrichment of translational methods in science is supported by an increasing body of published knowledge. The information presented on the following topics is limited to personal experience. I consider the two methods examined below, viz. Action Research and Translational Science, worthy of deeper inquiry as relevant contemporary bridging approaches.

\section{Action Research}

Critical elements at the centre of participatory action research (PAR) usually involve three actions, i.e. 'plan ... act ... reflect'. However, these actions have been applied in different sequences and can express different researchers' experience. These include: the continuing 'plan-act-observereflect' cycle; the 'observe-reflect-create-apply' model and the experimental learning mode 'plan-action1-reflect-generalise - re-plan-action2reflect-generalise' sequences (Hynes, 1999a). Ian Plowman (pers. comm., 2000) considers it is more realistic to think of the process as a continuing spiral rather than a series of cycles. The key to PAR is reflection on current practice (McTaggart, 1991, 1998). I have respectively used the 'plan-act-reflect' approach in a two-cycle strategy with the Desert Uplands Build-Up and Development Committee in two case studies (Hynes, 1999a), and the 'observereflect-create-apply' approach with the Savannah Guides (Hynes, 1999b).

Regarding the ongoing perceived disconnect 
between scientists and farmers, I quote Dr Jim Davie, former research manager and senior researcher QNPWS:

In my view the basis for farmers' complaints with scientists is that scientists tend to research the same questions generated by their own disciplinary and theoretical foundation. Through the Land Care movement of the 80's farmers gained a stronger voice at the land management decision-making table and were able to influence the way federal money flowed. For a while they were successful in taking control - much to the frustration of the old school of DPI scientific business. Then scientists wrested it back and the farmers fell out of the loop again.

I think by acknowledging the value of a model where scientists work with farmers to identify the scientific questions that farmers grapple with but cannot enunciate in terms that science can address, would be very productive. This is the model central to the approach of the MS Swaminathan Research Foundation in Chennai, India. Perhaps that [approach] would take the debate somewhere positive. Action Research and Translational Science! (J. Davie, pers. comm., 2021).

\section{Translational Science}

This is the nexus where knowledge meets action. It is situated at the intersection of a broad spectrum of institutions and information pathways where scientists, practitioners and stakeholders work together to build trust and develop ideas, products and outcomes that are accessible and actionable. Translational ecology, for instance, must comprise more than clear speech, lexical equivalence and good intentions. To be effective it requires understanding of the languages, cultures and currencies of policy, management and the societies in which relevant decisions are made. Here, real-world contexts need to be understood to enhance the likelihood of acceptance and then good application (Enquist et al., 2017; Hynes, 2020). Parallel integrating and communication strategies are needed for all streams of scientific enterprise if workable, community-owned applications are to succeed. Clearly, approaches such as those overviewed are needed across the full spectrum of scientific endeavour if we are to ethically strengthen the quality of science communication to the wider community.

\section{Peer Review as a Foundation of Public Trust in Science}

It was in 1665 that the Royal Society, based initially in Oxford University and then in London, published what was arguably the first scholarly journal dedicated to science: Philosophical Transactions, Giving some Account of the present Undertakings, Studies, and Labours of the Ingenious in many considerable parts of the World. The first editor wrote that "We must be very careful as well of regist'ring the person and time of any new matter, as the matter itselfe, whereby the honor of the invention will be reliably preserved to all posterity" (Oldenburg, 1664). This crystallised the primary distinctive features of a scholarly journal: registration (date stamping and provenance), certification (peer review), dissemination and archiving. It is on this foundation that the body of scientific knowledge has expanded, article by painstaking article, to the present day.

In other words, scientific knowledge is recorded, validated by knowledgeable experts and built into the foundations of future knowledge. Peer review is not a guarantee against fraud or error, for weak research may be exposed only after experiments are repeated by others, and sometimes this may take years or decades. But peer review is a first line of defence, a filter that sieves out most weak research and improves even good research. Understandably, it is of ongoing concern to the science community that the cases of substandard research that come to public attention only give weight to those who find scientific advices inconvenient.

Most people do not have a strong or rigorous understanding of the scientific process and its ongoing evolution. Scientific research, whatever the path, is a dynamic process seeking to find a closer, more accurate understanding of reality. So, scientists learn to live with a degree of ambiguity regarding their work and its interpretation. Each new finding usually takes human knowledge one step closer to a more complete understanding. Sometimes the scientific process leads up blind alleys and mistakes occur. Science learns from such mistakes. However, the wider public generally 
prefer definitive, black-and-white answers. A subset of society is threatened and frustrated by uncertainty and by whatever inconvenient interim truths may be revealed by scientists, even though such findings are steps on the way to a deeper understanding of the subjects or problems under investigation.

An opinion piece by the Chief Executive Officer of AgForce, Queensland's peak body for broadacre agriculture, in Queensland Country Life on 1 July 2021, (Guerin, 2021a, p. 18), displays this propensity to cast doubt on inconvenient scientific information. The article commences unremarkably enough:

We live in a confusing time - where opiniondominated social media and sophisticated marketing tactics overshadow seemingly outdated virtues like reason and fact.

The article then proceeds to rail against the Reef Scientific Consensus Statement (Anon., 2020; https://www.reefplan.qld.gov.au/science-andresearch/the-scientific-consensus-statement), used by the Queensland Government as justification for a raft of regulations designed to protect the Great Barrier Reef. The government's website explains that the Consensus Statement "draws on independent, peer reviewed research from more than 1600 reports. A panel of 48 experts from a range of disciplines (for example biology, ecology, economics and social science) compiled the document".

The conclusions of the Consensus Statement have been unpalatable to AgForce, which disparaged it as peer-reviewed not by independent scientists but by "friends and colleagues close to them ... to support the views of the gang of 48 most of whom were dependent on reef funding for their jobs" (Guerin, 2021a, p. 18).

AgForce is correct to observe that government reports, even when written by credentialled scientists, are not necessarily peer-reviewed by anonymous, disinterested referees, as is the norm for scientific journals, but to dismiss the Consensus Statement in such ad hominem terms displays a worrying lack of trust in the honesty of people and public institutions established to translate science into policy. This column could be dismissed as a piece of political theatre, except for the announcement that:
This is why AgForce is so hellbent on getting an Office of Science Quality Assurance up and running - to validate the authenticity of ALL science, not only that related to the reef (Guerin, 2021a, p. 18).

My response was published in Queensland Country Life on 22 July. I argued that:

Our era is saturated with 'spin'. It is commonplace that politicians, commentators and lobbyists offer distorted or partial facts as the 'real truth'. If rural communities are to resolve the complex challenges cascading upon them, they must have access to trustworthy knowledge, the best antidote to spin.

In arguing for an Office of Science Quality Assurance to "validate the authenticity of ALL science" relevant to Queensland, the CEO of AgForce may be desiring to improve the reliability of scientific knowledge, but such an office is likely to have the diametrically opposite effect.

The publication of the first scientific journal, in 1665 , by the Royal Society of London, ushered in an era of rapid expansion of scientific knowledge that continues.

The core tool in this expansion of knowledge has been the peer-reviewed journal. The entire body of scientific knowledge rests on a commitment to peer-review, reproducibility and caution in drawing conclusions. The Royal Society of Queensland stands in this proud tradition and has recently published the 128th edition of its peer-reviewed Proceedings.

AgForce, a partner since May 2018 with the Society in the Rangelands Policy Dialogue, seems to be proposing that only scientific knowledge approved by the government should find its way into policy. Every significant scientific finding would become fodder for partisan argument. Independent investigation would be suffocated as only state-endorsed research programs would be deemed worth pursuing.

It would not be possible to constitute an Office of Science Quality Assurance without political complexion. The office would be vulnerable to stacking with political appointees, meaning that the direction of scientific research would seesaw from one administration to another as 
partisan enthusiasts grabbed the privilege of appointment.

A new office would also undermine the traditional capacity of the public service to provide trustworthy advice. Any disparity between advice from these two sources would be elevated to ministers to resolve, further politicising what ought to be objective scientific findings ...

Through peer-reviewed publication, the entire international science community strives to avoid distortions and to bring its expertise to bear on the challenges facing humanity from the pressures being placed on the earth's resources. Yes, like all human endeavours, the process has shortcomings and lapses, but the remedies lie more in reforming the procedures by which research is funded than in adding another statesanctioned layer of procedures on top (Hynes, 2021a, p. 21).

The CEO of AgForce responded in a column published on 3 August:

But from where AgForce, other industry groups, and rural communities and producers stand, science has been in bed with political parties of all colours and stripes for decades ...

Science has, in fact, with each passing decade and astonishing advancement, become less trustworthy because of the very 'spin' Dr Hynes would like politicians, commentators, and lobbyists to avoid ...

In calling for a national Office of Science Quality Assurance, AgForce and industry groups are pursuing a reform into 'trustworthy knowledge', untarnished by politics, activists, or funding-dependent scientists.

Why any scientist worth his salt would question that level of independent oversight and rigour should perhaps be the subject of its own independent analysis (Guerin, 2021b; https://www. queenslandcountrylife.com.au/story/7367482/ science-and-politics-already-joined-at-the-hip/).

Interpreting this as a direct challenge on the independence of the Society, I responded on behalf of its members and the Queensland scientific community with a column published on 10 August. In it I claimed that:

AgForce has misunderstood the real gap in the suite of bodies working at the interface between science and farming. Science arrives in piecemeal findings, presented via articles in disparate journals and via official reports from various jurisdictions. It arrives at different scales, different levels of complexity and with widely varying implications for practical action ... A multilateral statutory authority established to produce comprehensive assessments of resource condition and trend, then to advise governments independently on opportunities and limitations for future land use, using a "whole systems" perspective, is likely to enjoy enthusiastic support from the scientific community (Hynes, 2021b, p. 19).

The need for a new trustworthy agency that would translate science as distinct from validating science, a traditional role of the peer-reviewed journals, was raised during the Rangelands Policy Dialogue co-organised by the Society in 2019 and 2020. This proposition, however, has gained little public traction and does not seem to be on the agenda of bodies representing farmers, who would have much to gain from a more orderly, transparent and trustworthy process of land-use decision making. By contrast, momentum seems to be building for a new office to cast judgement on scientific advice sourced from research. At the July 2019 Convention of the Liberal National Party in Brisbane, a motion was passed calling on an incoming LNP government to establish an Office of Science Quality Assurance (Birmingham, 2019). Reportedly, the National Party's Federal Council shortly afterwards in 2019 endorsed a motion to establish a national scientific quality assurance agency (Johnson \& Walker, 2019). On 14 October 2021, the Institute of Public Affairs launched an appeal for funds for a "Project for Real Science" (https://ipa.org.au/).

So, far from building public institutions that will use peer-reviewed scientific knowledge as a basis for public policy making and decision making, we now see a campaign to undermine confidence in peer-reviewed science and/or in the credibility of scientists employed in public agencies whose role involves interpreting peer-reviewed science.

The published advocacy by AgForce, associated conservative parliamentarians and the Institute 
of Public Affairs expresses little concern about the parsimonious funding for scientific research, casualisation of the scientific workforce, the corporatisation of universities or the underfunding of public interest scientific bodies that can explain a great deal of such weaknesses that may exist in the conduct of scientific research in this country.

As my predecessor Dr Geoff Edwards has observed (Edwards, 2018, pp. 73-74):

Science, like any other human endeavour, is an imperfect process. What makes science robust, however, is its relentlessly self-critical approach. Like opposing barristers, scientists continually challenge each other, but with consensus gradually building over time as the position best supported by evidence prevails.

Science replaces private prejudices with publicly verifiable evidence. Admittedly, some journals, notably those termed 'vanity journals', are known to take shortcuts with editorial review. It is also true that in some disciplines, false leads can be pursued for years before being invalidated. But none of these imperfections should be used to undermine public and political trust in the essential veracity of scientific research.

No-one close to the editorial process for a journal run by a not-for-profit society like our own, conducted by unpaid volunteers, evaluating articles by authors not paid for their submission and printed at the expense of members, could doubt that the entire process is driven by a desire to expand knowledge in the public interest. Nor could they doubt the earnestness with which those responsible seek to uncover and eliminate mistakes.

David Lloyd, an author in our Proceedings Volume 127, has expressed this astutely:

I do agree that an office of 'scientific oversight', as apparently suggested by Agforce, would be completely regressive. The broad, world-wide, peer review process for scientific publication is time-honoured, underpinning the landmark research done across the decades in Australia and other countries, right up to the present ... (David Lloyd, pers. comm., 2021).

\section{Concluding Remarks}

There are many techniques that conduce towards reliability of scientific knowledge, as well as dispatching research reports to externally independent referees. Internal institutional reviews, commitment to ethical codes of practice, embedded research ethics, coalitions of qualified, critical, analytical and sceptical reviewers, disciplinary and crossdisciplinary conferences and seminars, parallel development of methods and theory have traditionally shaped the preparation of research reports for publication and will continue to do so.

However, the communication of scientific findings to wider society, relevant stakeholders and key decision makers largely lies outside these procedures. This is an ongoing, seemingly formidable challenge. Clearly, there is a pressing imperative to improve the transfer of scientific knowledge and enable end-users to action useful findings for the betterment of all society.

A rigorous, evolving framework for fact-checking science communication for wider audiences is under development, viz. the European Unioninitiated $\mathrm{ENJOI}^{4}$ project, which has grown out of the need to counter the misinformation, i.e. the "Infodemic" (Alam \& Chu, 2020), which has caused great confusion and often tragic consequences during the COVID-19 pandemic.

Standards, principles and indicators for effective science communication to the community are being rapidly assessed, developed and strengthened. These include criteria and performance indictors:

- Ethical rules: Avoid being an advocate; be fair to differing viewpoints.

- Rigour: Use reliable, rigorous and relevant sources; fact-check uncertain text.

- Sources: Persistently use reliable, rigorous and verifiable sources.

- Networking: Establish good networking with all key actors.

- Target audience: Approach the communication as a service to the public.

- Engagement: Ensure effective, ethical bidirectional communication.

- Newsworthiness: Present new, impact-rich knowledge.

\footnotetext{
${ }^{4}$ Engagement and Journalism Innovation for Outstanding Open Scientific Communication (EU).
} 
- Perspective: Set the topic in a temporal, scientific and social context.

- Message and language: Use clear, correct, comprehensible language.

- Story telling: Tell a story whose subject represents the scientific data to be conveyed.

- Media format: Use innovative, creative formats to engage the widest audience.

- Video and audio: Plan content and practice before producing.

- Scientific posters: The title is the main conclusion; use a flow chart format.

- Social media: The pace and dynamics of conversations differ across platforms; it is essential to adapt strategies to the public's habits and use in this complex digital environment.

- Infographics: Include at least one main theme, e.g. causal properties, causal processes, a key scenario, statistical analyses, measures of physical magnitude.

- Structure: Clear and ordered, with a focus on a central idea or a few key points.

- Impact: Pay attention to life-related issues and what can be done to solve problems.

This process and the resulting strategy and communication framework can assist in reaching the necessary standards to counterbalance fake memes and misinformation that so easily spread in our time. We need to use it or a similar effective approach when communicating Queensland- and Australia-wide science.

Society-wide, persistent, clear and accurate communication and public education are essential in developing and maintaining the public's trust in science. There is required a dedicated approach to encouraging and educating politicians and bureaucrats on the essential need to consistently incorporate rational scientific information into their policies and decisions. This is a very difficult process in a world where people are exposed to short or obtuse media or internet grabs. Nevertheless, we need to urgently develop and apply the best strategies we can identify. This is a demanding task, especially for civil society bodies lacking the resources of government and business.

The framework presented above suggests a path that could substantially increase the effectiveness of science communication to the wider community. And therein lies another lesson that we can draw from the foregoing narrative: the lack of resources for those involved in and defending public-good science lies at the heart of many of the ills that are perceived, both by scientists and their critics. Lack of resources is a policy setting that is open to policy remedies.

\section{Acknowledgements}

Special thanks are due to Dr Geoff Edwards for valuable assistance in editing the text on the QCL debate and other helpful advice, and to other members of the Council of The Royal Society of Queensland for their valuable comments.

\section{Literature Cited}

Alam, N., \& Chu. C. (2020). Covid-19 Pandemic: Tackling 'Infodemics' through an integrated one healthsocial science approach. Proceedings of The Royal Society of Queensland, 128, 99-111.

Anon. (2020, 10 November). Reef scientific consensus statement. Great Barrier Reef. https://www. reefplan.qld.gov.au/science-and-research/the-scientific-consensus-statement

Anon. (2021, 14 August). Climate change - A new reality. The Economist (pp. 61-63).

Balch, J. K., Nagy, R. C., \& Halpern, B. S. (2019). NEON is seeding the next revolution in ecology. Frontiers in Ecology and the Environment, 18(1), 3. https://doi.org/10.1002/fee.2152

Birmingham, J. (2019, 16 July). LNP had doublespeak down to a science at convention. The Age. https:// www.theage.com.au/national/queensland/np-had-doublespeak-down-to-a-science-at-convention20190716-p527lz.html

Brooks, M. (2021). Quantum frontiers. New Scientist, Special Issue No. 3349, 34-43.

Darwin, C. (1859). On the origin of species by means of natural selection, or the preservation of favoured races in the struggle for life. Murray. 
Edwards, G. (2018, 14 January). Tide of evidence shows that the Reef is in need of our help. The Sunday Mail (pp. 73-74). https://www.couriermail.com.au/news/opinion/opinion-sound-science-showsgreat-barrier-reef-needs-our-help/news-story/978ffe1b41c20b86fabb66a9528d05ff

Einstein, A. (1905a). Uber einen die Erzeugung und Verwandiung des Lichtes betreffenden heuristischen Gesichtspunk. Annalen der Physik, 14 (Supp.), 164-181. ${ }^{5}$ https://doi.org/10.1002/andp.200590004

Einstein, A. (1915). Die Feldgleichungen der Gravitation. SitzungsbericheBerlin; Koniglich Preussische Akademie der Wiisenschaften. ${ }^{6}$

ENJOI. (2021). Engagement and journalism innovation for outstanding open scientific communication. European Union. https://enjoiscicomm.eu

Enquist, C. A. F., Jackson, S. T., Garfin, G. M., Davis, F. W., Gerber, L. R., Littell, J. A., Tank, J. L., Terando, A. J., Halpern, B., Kiers, J. K., Morelli, T. L., McNie, E., Stephenson, N. L., Williamson, M. A., Woodhouse, C. A., Yung, L., Brunson, M. W., Hall, K. R., Hallett, L. M., Lawson, D. M., Moritz, M. A., Nydick, K., Pairis, A., Ray, A. J., Regan, C., Safford, H. D., Schwartz, M. W., \& Shaw, M. R. (2017). Foundations of translational ecology. Frontiers in Ecology and the Environment, 15, 541-550. https://doi.org/10.1002/fee.1733

Gibbon, M., Limoges, C., Nowotny, H., Schwartzman, S., \& Trow, M. (1994). The new production of knowledge - The dynamics of science and research in contemporary society. Sage Publications Ltd. https://doi.org/10.4135/9781446221853

Guerin, M. (2021a, 1 July). Fear, not facts now shapes the views of most. Queensland Country Life (p. 18). Guerin, M. (2021b, 3 August). Opinion: Science and politics already joined at the hip._Queensland Country Life. https://www.queenslandcountrylife.com.au/story/7367482/science-and-politics-already-joined-atthe-hip/

Hawking, S. W. (1988). A brief history of time - from the big bang to black holes. Bantam Books.

Heisenberg, W. (1930). The physical principles of the quantum theory. University of Chicago Press.

Hynes, R. A. (1979). Environmental problems, theoretical links and interdisciplinary practice. Griffith University, School of Australian Environmental Studies, W/P No. 5/79.

Hynes, R. A. (1981). Agricultural land, soil resources and broader environmental considerations. Bulletin, Australian Institute of Agricultural Science, Queensland Division, 236, 12-17.

Hynes, R. A. (1998). Revegetation of disturbed sites in tropical and sub-tropical ecosystems. (Vol. 1: The Ecological and Environmental Context). Background Readings for Revegetation of Disturbed Sites, James Cook University, Tropical Savannas Cooperative Research Centre.

Hynes, R. A. (1999a). Participatory action research for integrated regional development in the Desert Uplands of Queensland. In S. McGinty (Ed.), Tertiary teaching book III. James Cook University Press, pp. 25-37.

Hynes, R. A. (1999b). Action learning and action research for ecotourism: the Savannah Guides program. [Conference paper] 7th National Conference, Ecotourism Association of Australia. Fraser Island, Queensland.

Hynes, R. A. (2015, 28 July). Seeking excellence in science education 2015 [Supplementary paper]. Science Education Think Tank. The Royal Society of Queensland and Office of the Chief Scientist Queensland, QUT.

Hynes, R. A. (2020). Science through a big window. Presidential Address. Proceedings of The Royal Society of Queensland, 128, 169-185.

Hynes, R. A. (2021a, 22 July). Let's keep politics out of science. Queensland Country Life (p. 21). Hynes, R. A. (2021b, 12 August). Science needs a translator. Queensland Country Life (p. 19).

\footnotetext{
${ }^{5}$ In 1905 Einstein published five papers; in the first he proposed that light is not a continuous wave, but consists of localised particles.

${ }^{6}$ Einstein presented his Theory of General Relativity on how gravity affects the fabric of space and time; this expanded his Theory of Special Relativity published 10 years earlier.
} 
IPCC. (2021). Sixth assessment report [Working Group contributions]. https://ipcc.ch/assessment-report/ ar6/

Johnson, E., \& Walker, K. (2019, 16 September). Separation of science and the state. Science and Technology Australia. https://scienceandtechnologyaustralia.org.au/separation-of-science-and-the-state/

Kosko, B. (1994). Fuzzy thinking: the new science of fuzzy logic. Flamingo, Harper Collins.

Kuhn, T. (1962). The structure of scientific revolutions. University of Chicago Press.

McCallan, E., Knott, J., Nunez-Mi, G., Taylor, B., Jo, I., \& Fei, S. (2019). Trends in ecology: shifts in ecological research themes over the past four decades. Frontiers in Ecology and the Environment, 17, 109-116. https://doi.org/10.1002/fee.1993

McTaggart, R. (1991). Principles for participatory action research. Adult Education Quarterly, 14(3), 168187. https://doi.org/10.1177\%2F0001848191041003003

McTaggart, R. (1998). Is validity really an issue for participatory action research in education. Reflect, l(2), 32-39. https://doi.org/10.1080/10245289808523513

Mendel, G. J. (1866). Versuche über Pflanzenhybriden. Verhandlungen des naturforschenden Vereines in Brunn (Vol. IV) (1865), 3-47. English Translation: Bateson, W. (1901). Experiments in plant hybridization. Journal of the Royal Horticultural Society, 26, 1-32.

Newton, I. (1726). Mathematical principles of natural philosophy ('Principia Mathematica') (Newton's 3rd ed. in English). ${ }^{7}$

Oldenburg, H. (1664). Letter to Robert Boyle. Royal Society Archives.

Popper, K. R. (1965). The logic of scientific discovery. Basic Books.

Popper, K. R. (1972). Objective knowledge: an evolutionary approach. Clarendon Press.

Southwell, G. (2013). 50 Philosophy of science ideas you really need to know. Quercus.

Watson, J. D., \& Crick, F. H. C. (1953). Molecular structure of nucleic acids - A structure for deoxyribose nucleic acid. Nature, 171, 737-738. https://doi.org/10.1038/171737a0

Wegener, A. L. (1929). Die Entstenhung der Kontinente und Ozeane (4th ed.). Brainschweig. Fredrich Vieweg \& Sohn Akt. Ges. English language translation: Wegener, A. L. (1966). The origin of continents and oceans (Translated from the 4th revised German edition by John Biram). Dover.

Hynes, R. A. (2021). Presidential Address 2021. Edges of science and challenges of communication: Confusion in the community and finding a way forward. Proceedings of The Royal Society of Queensland, 129, 93-105. https://doi. org/10.53060/prsq.2021.pres

\footnotetext{
${ }^{7}$ Four full translations in English of the 'Principia' have appeared, all mainly based on Newton's third edition in English of 1726. These comprise the 1st by Andrew Motte (1729); 2nd by I. Bernard Cohen, Anne Whitman with Julia Budenz (1999), University of California Press; 3rd by Ian Bruce, published with other Enlightenment mathematicians (last updated 2021); and the 4th by Charles Leedham-Green (2021). Motte's version was timely as Newton died in 1727.
} 